\title{
Effect of inhaled steroids on lung function in young children: a cohort study
}

\author{
C.S. Devulapalli*\#, G. Haaland ${ }^{\#}$, M. Pettersen ${ }^{\#, *}$, K.H. Carlsen*, K.C. Lødrup Carlsen ${ }^{\#}$
}

Effect of inhaled steroids on lung function in young children: a cohort study. C.S. Devulapalli, G. Haaland, M. Pettersen, K.H. Carlsen, K.C. Lodrup Carlsen. (C) ERS Journals Ltd 2004.

ABSTRACT: The objectives of the present study were to determine the use of inhaled corticosteroids (ICS) for treating recurrent bronchial obstruction (rBO) in young children up to 2 yrs of age and to assess possible modifying effects of ICS on lung function in young children with rBO. From an observational, noninterventional birth cohort of 3,754 newborn children (3,697 with complete questionnaire data by 2 yrs of age), 306 children with documented rBO by age 2 yrs (cases) were identified along with 306 matched controls.

Two tidal flow/volume measurements were taken, one at presentation of disease (children were steroid naïve) and one at 2 yrs of age (mean age 11.2 and 25.6 months, respectively), from: 21 cases who subsequently received ICS (ICS+); 33 who did not (ICS-); and in 15 controls. The mean \pm SD duration of ICS treatment was $10.3 \pm 6.5$ months. The main outcomes were treatment with ICS and baseline ratio of time to peak expiratory flow/total expiratory time ( $t$ PTEF/tE).

From the entire cohort, 77 children $(2.1 \%)$ and $21 \%$ of children with $\mathrm{rBO}$ had received ICS by 2 yrs of age. Baseline $t \mathrm{PTEF} / \mathrm{t} \mathrm{E}$ was significantly lower at the first visit only in ICS + as compared to ICS- subjects, as well as in ICS+ and ICS- as compared to controls. The mean difference in baseline $t \mathrm{PTEF} / \mathrm{tE}$ from first to second visit was borderline statistically significant in the ICS + group only and correlated significantly with duration of ICS treatment.

The present observational cohort study demonstrated that one-fifth of young children with recurrent bronchial obstruction had received inhaled corticosteroids. Early inhaled corticosteroid treatment improved lung function by age 2 yrs, mostly in those with the longest duration of treatment.

Eur Respir J 2004; 23: 869-875.
*Voksentoppen Asthma and Allergy Centre, National Hospital of Norway, and ${ }^{\#}$ Dept of Paediatrics, Division of Woman and Child, Ulleval University Hospital, Oslo, Norway.

Correspondence: C.S. Devulapalli

Voksentoppen BKL

National Hospital of Norway

Ullveien 14

N-0791 Oslo

Norway

Fax: 4722136505

E-mail: c.s.devulapalli@medisin.uio.no

Keywords: Asthma

bronchial obstruction

children

inhaled corticosteroids

tidal flow/volume loops

wheezy infants

Received: August 202003

Accepted after revision: January 52004

The ECA study was supported by grants from the Norwegian Research Council. Astra Zeneca, Oslo, Norway has provided an educational grant for the first author.
There is little information available concerning how often inhaled steroids are used during the first 2 yrs of life for treatment of obstructive airways disease (OAD). Furthermore, limited information is available regarding modifying effects of inhaled corticosteroids (ICS) on the development of lung function in early life. In studies of asthmatic children $>6$ yrs old, one controlled prospective study [1] concluded that early treatment with ICS after the diagnosis of asthma established improved growth of lung function. In addition, an uncontrolled retrospective study [2] demonstrated significantly lower lung function growth in children treated with bronchodilators alone, as compared to those receiving antiinflammatory treatment with ICS or sodium cromoglycate. Conversely, a long-term study of inhaled budesonide failed to demonstrate any effect upon lung growth [3]. In this study, however, a mean time period of 5 yrs had elapsed from establishment of asthma diagnosis to commencement of the study. Recently, a large randomised placebo-controlled study of inhaled budesonide, starting $<2$ yrs after the diagnosis of asthma and including 7,241 patients from 32 countries, reported improved lung function both pre- and postbronchodilator after 1 and 3 yrs [4]. Although this study included

For editorial comments see page 795. patients of 5-66 yrs, similar findings were made in the age group 5-10 yrs consisting of 1,974 children [4].

Although ICS improve lung function in older asthmatics, it is still unclear whether or not ICS affect lung function measured objectively in children $<2$ yrs old with recurrent wheezing. Although various methods have been employed for objective assessment of airways and lung function in young children [5], no consensus has been reached on the optimal measure or method of lung function assessment in very young children.

Randomised, double-blind, placebo-controlled clinical trials suggest the beneficial effect of ICS therapy on lung function in children with chronic wheezing [6], persistent wheezing after bronchiolitis [7, 8] and severe infantile asthma $[9,10]$. However, other studies report no such improvement in lung function of infants with recurrent wheezing [11]. In large epidemiological studies, it is beneficial to employ lung function measurements that can be easily performed with minimal discomfort and cooperation by the child. In line with these arguments, the shapes of tidal flow/volume (TFV) loops represented by the ratio of time to peak expiratory flow/total expiratory time $(t \mathrm{PTEF} / \mathrm{t} \mathrm{E})$ are reported to reflect $\mathrm{OAD}$ in adults [12], and children [13-17], and additionally predict wheeze in children $<3$ yrs old $[16,17]$. Thus, such measures could be used to assess possible effects of ICS treatment on 
the development of lung function in children with recurrent bronchial obstruction (rBO).

Based upon a real life prospective birth cohort study (Environment and Childhood Asthma (ECA) study in Oslo) [18], the main objectives of the present study were to assess how often ICS are used for the treatment of rBO during the initial $2 \mathrm{yrs}$ of life and, additionally, to assess possible modifying effects of ICS therapy on lung function in children during this time period.

\section{Subjects and methods}

\section{Study design}

The present study arises from the ECA study in Oslo [18], in which 3,754 healthy newborn children ( $>2 \mathrm{~kg}$ birth weight) were enrolled at birth in the two main Oslo hospitals (Aker Hospital and Ullevål Hospital) January 1992-March 1993. Eligibility criteria for enrolment in the main study, as well as the nested case-control study, are described in detail elsewhere [18], but will be briefly outlined below. The study was approved by the Regional Medical Ethics Committee, and all parents of the participating children gave their written informed consent.

All children were followed half-yearly from birth until their second birthday with questionnaires completed by the parents/guardians, with the first time being in the maternity ward. Questions included: family history of atopic, or other, diseases; parental smoking habits; health of the child (respiratory, allergic, skin, as well as general diseases); and details about medical treatment, including ICS. All questionnaires were scrutinised for possible symptoms of bronchial obstruction (BO) to identify children with possible rBO (cases) for the nested case-control study. Clinical signs with a relationship to $\mathrm{BO}$ were recorded on a check-box card by all doctors examining a participating child during a respiratory tract illness, and the cards were returned to the study personnel at least every 6 months for identification of a possible case. All family doctors, well-baby clinics, accident and emergency departments, and regional paediatric hospital wards were requested to refer participating children with possible or established BO to the study paediatrician. Any of these events led to a request to attend a clinical examination by the study paediatrician for eligibility to enrol in the nested case-control study.

Cases $(n=306)$ were defined as children who had experienced at least two episodes (or one persistent period lasting $>4$ weeks) of $\mathrm{BO}$ before 2 yrs of age. A child with no symptoms or indicating signs of BO by 2 yrs, born closest in time to a defined case, was identified as one control per case. All children were asked to attend one or two visits (depending upon age at enrolment in the case-control study: one visit if $>20$ months, two if $<20$ months). The first visit (visit 1 ) was performed as soon as possible after eligibility was established and visit 2 as close as possible to the second birthday, ensuring that the children were without symptoms of ongoing respiratory tract infection at the time of investigation.

The visits included clinical examination; lung function by TFV loops, baseline and after salbutamol; and blood samples drawn for markers of inflammation and total immunoglobulin (Ig)E. Additionally, skin-prick test (SPT) and blood sampling for specific IgE-analyses were performed at visit 2 .

\section{Subjects}

The study profile, showing the birth cohort with the nested case-control design, including the children attending visit
1 and 2, as well as the use of ICS and lung function measurements, is depicted in figure 1. Three groups of children are described for the present study.

The first group of children included all children from the entire cohort who had completed all four follow-up questionnaires $(3,697$ out of 3,754), as well as all children defined with rBO who had attended at least one visit. This group created the basis for the first aim; how often ICS are used in children $<2$ yrs. Of the 306 identified children with rBO, 18 did not attend any visit, 163 attended the first visit, 265 the second visit and 140 attended both. Of the 306 children identified as controls, 87 attended the first visit, 251 attended the second visit and 63 attended both (fig. 1).

The second group of children, included in the present study to assess possible effects of ICS on lung function, comprised those 54 cases ( 28 males) and 15 cases ( 4 males) in whom lung function measurements had been obtained on both occasions ( $40 \%$ of all children attending both visits). ICS had been used by 21 children (ICS+) out of the 54 cases $(39 \%)$. Details of the demographic data for the subjects are given in table 1.

The third group of children, used only for assessing the representativity of the included 69 children $(54$ cases and 15 controls), comprised of the remaining 243 children (110 with rBO and 133 controls) who had lung function measurements obtained at visit 2 only and the remaining 37 children (19 with rBO and 18 controls) with lung function measurements obtained at visit 1 only. Demographic data were compared to the 243 children at visit 2 , with lung function measured at this time only. Baseline lung function data were compared between the 69 children at visit 1 and 2, respectively, with the additional 37 children and 110 children, with lung function measurements at this time only.

Medical treatment was administered by each child's regular doctor, and the study personnel had no influence on the

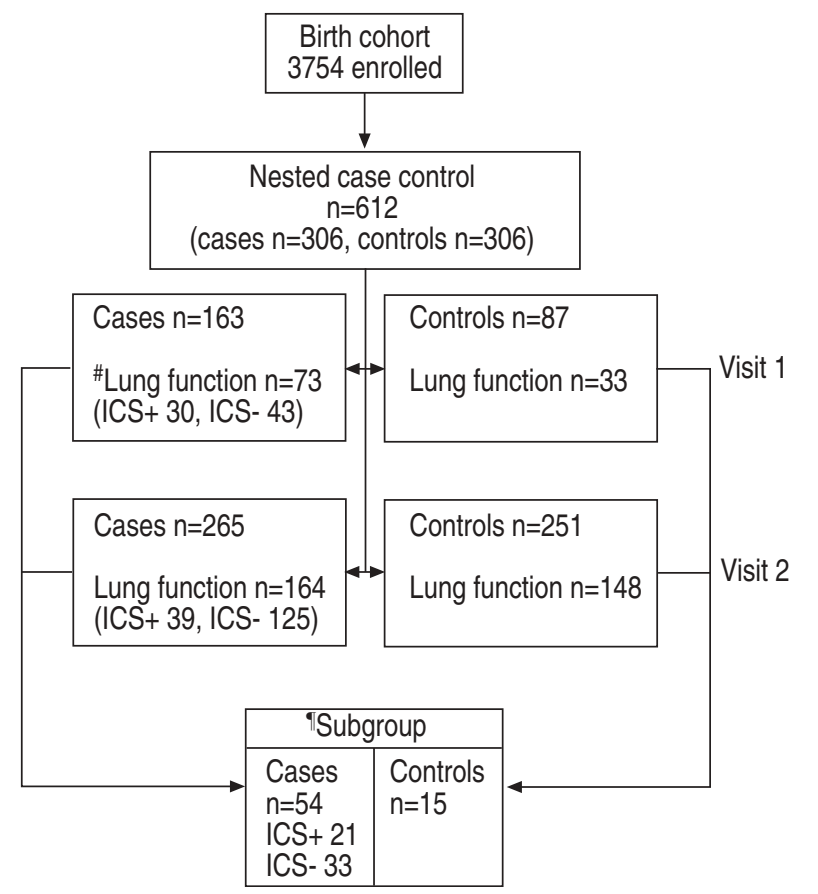

Fig. 1.-Study profile of subjects. The boxes related to visit 1 and visit 2 , show the number of children who attended clinical examination at first and second visit, respectively. None of the children received inhaled corticosteroids (ICS) before visit 1. ICS+: children who received ICS by 2 yrs of age; ICS-: children who did not receive ICS by 2 yrs of age. \#: children who had successful lung function measurements; ": all children with lung function measurements on both visits. 
Table 1.-Demographic variables and baseline characteristics of 54 children with recurrent bronchial obstruction and 15 controls

\begin{tabular}{|c|c|c|c|c|}
\hline Characteristics & $\mathrm{ICS}+$ & ICS- & Cases & Controls \\
\hline Subjects n & 21 & 33 & 54 & 15 \\
\hline Boys & $12(57)$ & $16(50)$ & $28(52.8)$ & $4(26.7)$ \\
\hline Age at first BO months & $5.0 \pm 3.8$ & $6.3 \pm 4.5$ & $5.8 \pm 4.5$ & \\
\hline Atopic dermatitis & $8(38)$ & $17(52)$ & $25(46.3)^{+}$ & $1(7)$ \\
\hline Parental atopy ${ }^{\#} \%$ & $11(52.4)$ & $21(65.6)$ & $32(60.4)$ & $6(40)$ \\
\hline Maternal smoking daily \% & 24 & 30 & 28 & 20 \\
\hline Age at visit 1 months & $10.3 \pm 4.8$ & $11.9 \pm 5.5$ & $11.2 \pm 5.3$ & $9.5 \pm 5.7$ \\
\hline Age at visit 2 months & $25.6 \pm 1.3$ & $25.5 \pm 1.8$ & $25.6 \pm 1.6$ & $26.3 \pm 2.3$ \\
\hline Weight at visit $2 \mathrm{~kg}$ & $13.1 \pm 1.6$ & $13.3 \pm 1.5$ & $12.9 \pm 1.6$ & $12.7 \pm 3.7$ \\
\hline Height at visit $2 \mathrm{~cm}$ & $89.2 \pm 3.7$ & $89.1 \pm 3.6$ & $89.1 \pm 3.6$ & $89.9 \pm 4.3$ \\
\hline Total IgE at visit 2 & $7.8(4.9-12.5)^{\S}$ & $18.3(11.8-28.4)$ & $12.9(9.3-18.1)$ & $8.6(4.7-15.8)$ \\
\hline Skin-prick test positive $\mathrm{n}$ & 0 & 2 & 2 & 0 \\
\hline
\end{tabular}

Data are presented as $\mathrm{n}(\%)$, mean \pm SD or geometric mean $(95 \%$ confidence interval) unless otherwise stated. ICS+: received inhaled corticosteroids (ICS) by 2 yrs; ICS-: subjects not received ICS by 2 yrs; BO: bronchial obstruction; IgE: immunoglobulin E. \#: reported parental asthma and/or rhino conjunctivitis; $^{\uparrow}$ : skin-prick test was considered positive with at least one allergen weal diameter of minimum half the histamine weal size. ${ }^{+}: \mathrm{p}<0.006$, when cases and controls are compared; $\$$ : $p=0.01$, when ICS + and ICS- were compared.

choice of treatment. All children were steroid naïve at the first study visit and $79 \%$ remained so until 2 yrs of age (ICS-). Mean \pm SD duration of treatment with ICS was $10.3 \pm 6.5$ months.

\section{Lung function measurements}

Measurements of TFV loops using SensorMedics 2600 system (Anaheim, CA, USA) were performed by trained investigators, and were attempted in all subjects awake and quietly breathing. Bronchodilators (short-acting) were withheld on the morning prior to testing and none of the children had received long-acting bronchodilators. The details of measurements are described elsewhere [19]. Briefly, TFV loops were obtained with a face mask (Vital Signs Inc., Totowa, NJ, USA) connected to pneumotachograph (4500 series; Hans Rudolph Inc., Kansas City, MO, USA) with a flow range of 0-30 L· $\mathrm{min}^{-1}$. Dead-space of the system was $2.4 \mathrm{~mL}$ and that of the face mask was $8.4-11 \mathrm{~mL}$. Volume was derived by the digital integration of the flow signal, which occurred at a sampling frequency of 256 samples $\cdot \mathrm{s}^{-1}$ without any filtering of the raw signal. Calibration of the flow and volume signals was performed daily, using a 100-mL precision syringe (Hans Rudolph Inc.).

Four representative TFV loops were stored for the final analysis. Each loop was chosen from eight stored loops, obtained from a series of breaths during established tidal breathing. The loops were selected from tidal breaths with as stable volume and shape of the loops as possible, and the respiratory rate as low as possible. Details of $t \mathrm{PTEF} / \mathrm{tE}$ ratio calculations have been described elsewhere [13, 19].

Bronchodilator responsiveness was assessed by TFV measurement immediately before and $15 \mathrm{~min}$ after inhaled nebulised salbutamol $\left(0.05 \mathrm{mg} \cdot \mathrm{kg}^{-1}\right.$ bodyweight $)$ as previously described in detail [13].

The main outcome measures were baseline $t \mathrm{PTEF} / \mathrm{t}$ E derived from TFV loops measured at visit 1 and visit 2 . Further outcomes were bronchodilator responsiveness, expressed as change in $t$ PTEF/ $t$ E from before to after salbutamol inhalation and given by the following formula:

$\left(t_{\mathrm{PTEF}} / t_{\mathrm{E}}\right.$ after salbutamol - baseline $\left.t_{\mathrm{PTEF}} / t_{\mathrm{E}}\right) \times$ baseline $t_{\mathrm{PTEF}} / \mathrm{t}_{\mathrm{E}}^{-1}$ as well as post bronchodilator $t \mathrm{PTEF} / \mathrm{tE}$ at both visits.

\section{Skin-prick test and IgE measurements}

SPT was performed, according to Nordic standard, in all children at age 2 yrs [20]. The following standardised extracts
(Greer Laboratories Inc., Lenoir, NC, USA) were used: egg white, cows' milk, Dermatophagoides pteronyssinus, timothy grass, cat dander, dog dander, silver birch, mugwort and Cladosporium herbarum, as well as saline negative control and histamine control $\left(10 \mathrm{mg} \cdot \mathrm{mL}^{-1}\right)$. Sensitisation was regarded as positive with a weal for the specified allergen at least half the size of a weal for the histamine positive control.

Total IgE was performed by UniCAP fluoroenzyme immunoassay according to the manufacturer's instructions (Pharmacia Upjohn, Uppsala, Sweden).

\section{Statistical analysis}

Results are given as mean $(95 \%$ confidence interval $(\mathrm{CI}))$, unless otherwise stated. The outcomes were compared between the groups (ICS+ and ICS-), and differences were assessed for statistical significance (provided there was normal distribution of the data in question) between unpaired groups by using the unpaired (two-sample) t-test and between paired groups using the paired (one-sample) t-test. Alternatively, the nonparametric Mann-Whitney or Wilcoxon signed-rank test were used, respectively. Correlation analyses were performed with Pearson's two-tailed test for significance. Demographic results were given as mean \pm SD. Differences were regarded as significant with $\mathrm{p}$-values $\leqslant 0.05$.

\section{Results}

Seventy-seven children $(2.1 \%)$ from the entire birth cohort and 64 of the 306 defined cases with $\mathrm{rBO}(20.9 \%)$ had received ICS for some reason by 2 yrs of age. The children with rBO did not differ significantly from controls in relation to age, sex, weight, height, positive SPT, daily maternal smoking, parental atopy or total IgE; whereas atopic dermatitis was significantly more frequent among cases (table 1). The ICS+ and ICS- groups were comparable, except for total IgE, which was significantly lower among the ICS+ as compared to ICSgroup (table 1).

The 69 included children did not differ significantly from the 243 nonincluded children (with lung function at visit 2 only) in respect to sex, weight, height, positive SPT, daily maternal smoking or parental atopic disease (data not shown); whereas age was significantly lower among the included children $(25.7 \pm 1.8$ versus $27 \pm 4.1$ months, respectively $(\mathrm{p}=0.004)$ ). Baseline lung function (prebronchodilator) did not differ significantly among the included 69 children as compared 
to the children with lung function measurements on one occasion only, neither at visit $1(0.24(0.21-0.27)$ versus 0.25 $(0.21-0.29)$, respectively) nor at visit $2(0.27(0.25-0.30)$ versus $0.28(0.27-0.29)$, respectively).

Mean duration of ICS treatment among the 21 ICS+ children with repeated lung function was $10.3 \pm 6.5$ months.

\section{Baseline lung function}

Baseline $t \mathrm{PTEF} / \mathrm{t}$ (prebronchodilator) at the first visit was significantly lower $(\mathrm{p}=0.03)$ in children who later received ICS as compared to those who did not, but there were no significant differences between the treatment groups in baseline lung function at age 2 yrs (table 2). Baseline $t \mathrm{PTEF} / \mathrm{tE}$ was significantly lower among children with $\mathrm{rBO}$ as compared to controls at both visits (table 2).

The mean difference in baseline $t \mathrm{PTEF} / \mathrm{t} \mathrm{E}$ from first to second visit was borderline statistically significant in the ICS+ group only $(0.057(-0.003-0.116), \mathrm{p}=0.06)$ (fig. 2) and correlated significantly with duration of ICS treatment $(r=0.481$, $\mathrm{p}=0.027)$.

At visit 2 , baseline $t \mathrm{PTEF} / \mathrm{tE}$ did not differ significantly between all the children who had received ICS by 2 yrs with lung function measurements $(n=39)$, as compared to the corresponding children $(\mathrm{n}=125)$ who had never received ICS (0.24 (0.21-0.28) versus $0.27(0.25-0.28)$, respectively, $\mathrm{p}=0.2)$. Analysis of the corresponding results for visit 1 confirmed the statistically significant differences with a mean difference in $t$ PTEF/t $\mathrm{E}$ in favour of the ICS- children $(0.07(0.03-0.12)$, $\mathrm{p}=0.003$ ).

\section{Bronchodilator responsiveness}

Among children with $\mathrm{rBO}$, but not among controls, bronchodilator responsiveness was significantly higher at visit 1 as compared to visit 2 (table 2), but without statistically significant differences between ICS + and ICS- children at either visit. Bronchodilator responsiveness at 2 yrs tended to correlate inversely with duration of ICS treatment $(r=0.43$, $\mathrm{p}=0.07$ ), but this was not statistically significant. There was no association between bronchodilator responsiveness at visit 1 (when the ICS+ children were steroid naïve) and later duration of ICS treatment.

Postbronchodilator $t \mathrm{PTEF} / \mathrm{t}$ E at visit 1 was obtained in 12 ICS +, 17 ICS- and eight control children, and corresponding numbers for visit 2 were 18, 28 and 12, respectively. At visit 1, $t \mathrm{PTEF} / \mathrm{t}$ increased significantly after inhaled bronchodilator both among ICS $+(\mathrm{p}=0.004)$ and ICS- children $(\mathrm{p}=0.05)$, but

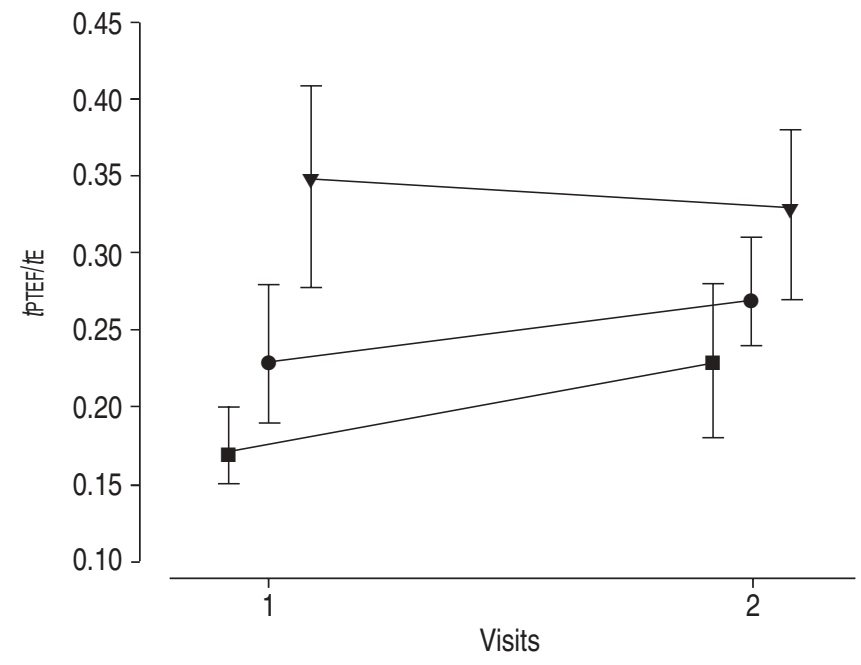

Fig. 2.-Baseline lung function in 54 children with recurrent bronchial obstruction and controls ( $\boldsymbol{\nabla})$ at enrolment in case-control study and at 2 yrs (visit 1 and 2, respectively). Lung function represented by the ratio of time to peak expiratory flow to total expiratory time ( $t \mathrm{PTEF} /$ $t \mathrm{E})$ was significantly lower among children who later received inhaled corticosteroids (ICS; ICS+: $\mathbf{a})$ compared to those who did not receive ICS (ICS-: - ) at first visit $(\mathrm{p}=0.03)$, but not at second visit $(\mathrm{p}=0.12)$.

not among controls (table 2). However, postbronchodilator $t \mathrm{PTEF} / \mathrm{t}$ E ratios were not significantly different between the ICS+, ICS- and control groups either at visit 1 or visit 2 (table 2).

Bronchodilator responsiveness did not differ significantly in relation to ICS treatment, neither at visit 1 nor visit 2 , but was significantly higher in children with $\mathrm{rBO}$ as compared to controls at visit $1(\mathrm{p}=0.02)$, but not at visit 2 (table 2 ).

\section{Discussion}

In the present observational, noninterventional, nested case-control, birth-cohort study, $2.1 \%$ of all children and $20.9 \%$ of all children with $\mathrm{rBO}$ had received ICS before $2 \mathrm{yrs}$ of age. Steroid-naïve children with $\mathrm{rBO}$ who later received ICS treatment had reduced lung function on the first visit ( $10-11$ months) as compared to those who did not, but the differences in lung function disappeared by 2 yrs. However, lung function was reduced on both visits among $\mathrm{rBO}$ children as compared to controls. The observed improvement in baseline $t \mathrm{PTEF} / \mathrm{t} \mathrm{E}$ between the first and second visit among the

Table 2. - Lung function (the ratio of time to peak expiratory flow/total expiratory time (tPTEF/tE)) in 54 children with recurrent bronchial obstruction (rBO) and 15 controls

\begin{tabular}{lcccc}
\hline & ICS+ & ICS- & rBO & Controls \\
\hline Subjects n & 21 & 33 & 54 & 15 \\
First visit & & & & \\
$\quad$ Baseline & $0.17(0.15-0.20)^{\#}$ & $0.23(0.19-0.28)$ & $0.21(0.18-0.24)$ & $0.34(0.28-0.41)^{* * *}$ \\
$\quad$ Post & $0.23(0.17-0.28)$ & $0.29(0.23-0.36)$ & $0.27(0.22-0.32)$ & $0.32(0.23-0.40)$ \\
$\quad$ Bronchodilator responsiveness \% & $55.7(28.5-82.8)$ & $53.8(11.7-95.8)$ & $54.5(29.9-80.1)$ & $-1.46(-21.8-18.9)$ \\
Second visit & $0.23(0.18-0.28)$ & $0.27(0.24-0.31)$ & $0.26(0.23-0.29)$ & $0.33(0.27-0.38)^{\bullet}$ \\
$\quad$ Baseline & $0.28(0.21-0.34)$ & $0.29(0.24-0.33)$ & $0.28(0.24-0.33)$ & $0.31(0.25-0.36)$ \\
$\quad$ Post & $26.1(2.0-50.1)$ & $18.7(-1.6-39.0)$ & $21.6(6.6-36.5)$ & $-1.50(-14.3-11.3)$ \\
$\quad$ Bronchodilator responsiveness \% &
\end{tabular}

Data are presented as mean ( $95 \%$ confidence interval). ICS+: children who received inhaled corticosteroids (ICS) by 2 yrs of age; ICS-: children who did not receive ICS by 2 yrs of age; baseline: prebronchodilator values; post: postbronchodilator values. \#: p<0.03, comparing ICS+ and ICSchildren; ***: $\mathrm{p}<0.001, ? \mathrm{p}<0.03$, comparing all cases to controls. The change in lung function from inclusion to 2 yrs of age approached statistical significance in the ICS+ children $(\mathrm{p}=0.06)$, but not the ICS- and control children. 
ICS + children was positively associated with the duration of ICS treatment.

Based upon clinical trials in older children, early introduction of ICS in the treatment of asthma has been recommended $[1,2]$. This is further supported by a recent randomised controlled trial in 7,241 patients, of whom 1,974 were children aged 5-10 yrs; reporting that long-term inhaled budesonide improved lung function and asthma control in patients with mild persistent asthma, as compared to placebo, when treatment was started $<2$ yrs after the diagnosis of asthma [4]. However, except from clinical trials of ICS in infants and young children with $\mathrm{rBO}$ after hospital admissions for acute bronchiolitis [7, 8, 21, 22] and in infants and young children with severe asthma $[9,10]$, little is known about the extent of use and the effect of ICS upon lung function in very young children. The present $2.1 \%$ reported use of ICS among all children in the birth cohort, and in one-fifth of children with $\mathrm{rBO}$, is thought to be the first prevalence report of ICS use in a prospective follow-up cohort study in very young children. The reported modest use of ICS in infants and young children with rBO in the community of Oslo is likely to be representative of the use in all Scandinavian countries. Recently, WENNERGREN et al. [23] reported, from the Gothenburg area, that an observed decrease in acute asthma hospitalisations in children $>4$ yrs was probably due to ICS use (based upon prescription statistics). The hospital admissions for acute asthma in those $<4$ yrs, however, had not decreased, but the prescription rates for ICS in this age group was not stated. Bi-yearly reported use of ICS in a prospective study is likely to reflect the use, rather than the prescription rate, of these medications. Thus, the findings add valuable information into the debated use of ICS in young children with rBO or asthma.

To the current authors' knowledge, this is also the first study to assess the possible modifying effect of ICS on lung function in infants and very young children with $\mathrm{rBO}$ in a noninterventional, observational large prospective cohort study. The present study in 0-2-yr-old children was performed in accordance with recent recommendations from the National Coordinating Centre for Health Technology Assessment in the UK [24]. Real life noninterventional cohort studies serve as important comparisons and corrections to the common randomised clinical trials with carefully selected cases and controls, and are, as such, recommended by the National Institute of Health, in the USA [25].

Lung function was reduced upon enrolment into the casecontrol study in the rBO children who later received ICS, as compared to those who remained steroid naïve, as well as compared to controls. It is believed this has not been previously reported. This finding may suggest that children with lower lung function are more disposed to severe $\mathrm{rBO}$, with the subsequent clinically observed requirement for potent antiinflammatory treatment.

The observed difference in baseline lung function related to ICS treatment at visit 1 had disappeared by visit 2 . To exclude the possibility that this finding could be due to lack of statistical power with the relatively low number of subjects, a further group comparison in relation to ICS treatment of all rBO children who had lung function measured at 2 yrs was performed. This did not alter the main finding (data not shown). Thus, it is believed that the lack of significant difference in baseline lung function related to ICS treatment at 2 yrs reflects a novel finding. Similarly, to ensure that the differences observed in relation to ICS treatment during visit 1 were not by chance, group comparisons were performed similarly for all 73 children (30 ICS+), with lung function measured on enrolment into the case-control study strengthening the reported results. It is, therefore, unlikely that the current findings are skewed by the limited number of subjects in the study for assessing effects of ICS on lung function.
Although a low number of children in the different groups with lung function measured at both visits may confer a possible weakness of the present study, all children enrolled into the case-control study on the visits were approached for lung function measurements. The relatively low number of lung function measurements obtained at both visits reflects the difficulty in obtaining representative lung function measurements in noncooperative young children.

The findings demonstrate that ICS in general were given to the children with the lowest lung function, albeit the prescribing physicians were ignorant of the lung function results. This observation strengthens the likelihood that these lung function measurements reflect severity of OAD in young children, as has been previously reported [13, 26]. Furthermore, it appears that the children who subsequently received ICS treatment had the greatest improvement in lung function by 2 yrs of age. Several studies support this finding; MAAYAN et al. [8] reported significant improvements in specific airways conductance (SGaw) and a small increase in forced expiratory flow at resting lung volume values in nine infants receiving inhaled beclomethasone dipropionate (BDP) for 2 weeks in a placebo crossover trial. KRAEMER et al. [27] reported an increase in SGaw and thoracic gas volume (measured by body plethysmography) after 6 weeks of inhaled BDP in infants with recurrent wheeze. Conversely, STICK et al. [11] found no difference in lung function, measured by rapid thoracic compression, related to inhaled BDP (by metered dose inhalers and large volume spacer) for 8 weeks; whereas a statistically significant effect on the bronchial responsiveness to histamine was reported.

The present observational study with a mean ICS treatment duration of 10 months did not correct for type of ICS, method of administration, frequency or dose used by the children. Despite these potential shortcomings, the observed increase in baseline lung function correlated with the duration of treatment with ICS. As changes (over time) towards normality may statistically be associated with regression towards mean, further analyses were performed in the ICS+, ICS- and control groups as described by ALTMAN [28], to assess whether this could explain the improvement in lung function observed in the ICS + group. The analyses demonstrated that this was not the case (data not shown). Regression towards mean is also unlikely in view of the marked differences between cases and controls in lung function, which change from visit 1 to visit 2 (fig. 2). Furthermore, in the present study, the groups of children were not selected on the basis of lung function values, which could introduce a risk of regression towards mean if extreme values were selected, but upon treatment received.

A systematic review by CALPIN et al. [29] (including 24 randomised double-blind, placebo-controlled studies, 10 of which included preschool children) concluded that ICS were effective in controlling childhood asthma. It was further suggested that ICS were usually more effective in children $>5$ yrs than in younger children, although this was not substantiated by statistical significance [29]. Several studies have demonstrated beneficial effects of ICS in infants and very young children with $\mathrm{rBO}$ after admission to hospital due to acute bronchiolitis [7, 8, 22]; whereas others have not [21].

Bronchodilator responsiveness was not related to the use of ICS in the present study. Although $t \mathrm{PTEF} / \mathrm{tE}$ improved after salbutamol at visit 1 , this was statistically significant for both ICS+ and ICS- children, with no significant differences between these two groups. It is not known if there are other studies in young children addressing this issue. However, both groups of $\mathrm{rBO}$ children had a significantly larger positive response to bronchodilator than the controls, which is supported by previous studies [13-17]. 


\section{Advantages and limitations of the present study}

In the present study, the observation of therapeutic effects, as prescribed during common clinical care, outweighs the possible limitation of ignoring carefully determined inclusion and exclusion criteria that are required for most drug trials. The design of this study ensured that treatment was decided by each child's own doctor, independent of the study. Thus, the observations reported were not likely to be due to observational bias. Furthermore, as demonstrated, the 54 rBO children with repeated lung function measurements were representative for all $\mathrm{rBO}$ children identified in this cohort study. The findings may, therefore, be generalised for populations similar to those in this study.

The number of infants and children treated with ICS in the present study could not be predetermined by power assumption and assessment of sample size, as can be done in controlled randomised clinical trials. Assessment of sample size for the ECA study was based merely upon the likely prevalence of $\mathrm{rBO}$, whereas the number of children receiving specific medical treatment depended upon the clinical practice in the area. In retrospect, the results indicate that the birth cohort would ideally require 500 extra children in the region for inclusion of another 10 children with $\mathrm{rBO}$ in a study like this. This is an argument for collaboration between large cohort studies, since such increases are costly both in time and money for any one centre.

Most studies addressing possible effect of ICS in children $<2$ yrs have reported effect on clinical symptoms only, probably due to the difficulties in obtaining measurements of lung function. Although there is debate on the standardisation and measurements in the youngest children, TFV measurements have been documented in the present study, in previous studies from the current authors $[13,16,26]$ and others' studies $[12,30]$, to be sensitive enough to differentiate between children with and without OAD, as well as to detect adverse effects of maternal smoking in pregnancy [31, 32]. It is, therefore, suggested that the present findings are representative of changes in lung function through early childhood, and can be used to document changes related to ICS treatment in groups of these young children.

\section{Conclusion}

In this study, $\sim 2 \%$ of all children from a birth cohort and $21 \%$ of children with recurrent bronchial obstruction had received inhaled corticosteroids by 2 yrs of age. Steroid-naïve children with recurrent bronchial obstruction and subsequent inhaled corticosteroid treatment had reduced lung function as compared to those who remained steroid naïve, and the improvement in lung function by age 2 yrs increased with increasing duration of inhaled corticosteroid treatment. Thus, not only is the choice of medical therapy determined by the clinical state of the child, but once started, it is also an environmental factor likely to influence later outcome. This factor should, therefore, also be taken into consideration when addressing the effects of environmental factors upon lung function.

Acknowledgements. The authors are indebted to the children and their parents for their participation in the study. A special thanks to M. Bruu at Ullevål University Hospital for her skilled assistance, as well as to P. Nafstad, L. Bakketeig and G. Botten at the National Institute of Public Health whose collaboration was essential for the performance of the ECA study.

\section{References}

1. Agertoft L, Pedersen S. Effects of long-term treatment with an inhaled corticosteroid on growth and pulmonary function in asthmatic children. Respir Med 1994; 88: 373-381.

2. König P, Schaffer J. The effect of drug therapy on long-term outcome of childhood asthma: a possible preview of the international guidelines. J Allergy Clin Immunol 1996; 98: $1103-1111$.

3. Long-term effects of budesonide or nedocromil in children with asthma. The Childhood Asthma Management Program Research Group. N Engl J Med 2000; 343: 1054-1063.

4. Pauwels RA, Pedersen S, Busse WW, et al. Early intervention with budesonide in mild persistent asthma: a randomised, double-blind trial. Lancet 2003; 361: 1071-1076.

5. Morgan WJ, Geller DE, Tepper RS, Taussig LM. Partial expiratory flow-volume curves in infants and young children. Pediatr Pulmonol 1988; 5: 232-243.

6. Noble V, Ruggins NR, Everard ML, Milner AD. Inhaled budesonide for chronic wheezing under 18 months of age. Arch Dis Child 1992; 67: 285-288.

7. Carlsen KH, Leegaard J, Larsen S, Ørstavik I. Nebulised beclomethasone dipropionate in recurrent obstructive episodes after acute bronchiolitis during the first two years of life. Arch Dis Child 1988; 63: 1428-1433.

8. Maayan C, Itzhaki T, Bar-Yishay E, Gross S, Tal A, Godfrey S. The functional response of infants with persistent wheezing to nebulized beclomethasone dipropionate. Pediatr Pulmonol 1986; 2: 9-14.

9. de Blic J, Delacourt C, Le Bourgeois M, et al. Efficacy of nebulized budesonide in treatment of severe infantile asthma: a double-blind study. J Allergy Clin Immunol 1996; 98: 14 20.

10. Ilangovan P, Pedersen S, Godfrey S, Nikander K, Noviski N, Warner JO. Treatment of severe steroid dependent preschool asthma with nebulised budesonide suspension. Arch Dis Child 1993; 68: 356-359.

11. Stick SM, Burton PR, Clough JB, Le Souef PN, Sly PD. The effects of inhaled beclomethasone dipropionate on lung function and histamine responsiveness in recurrently wheezy infants. Arch Dis Child 1995; 73: 327-332.

12. Morris MJ, Lane DJ. Tidal expiratory flow patterns in airflow obstruction. Thorax 1981; 36: 135-142.

13. Carlsen KH, Lødrup Carlsen KC. Tidal breathing analysis and response to salbutamol in awake young children with and without asthma. Eur Respir J 1994; 7: 2154-2159.

14. Lodrup Carlsen KC, Stenzler A, Carlsen KH. Determinants of tidal flow volume loop indices in neonates and children with and without asthma. Pediatr Pulmonol 1997; 24: 391396.

15. Benoist MR, Brouard JJ, Rufin P, Delacort C, Waernessyckle S, Scheinmann P. Ability of new lung function tests to assess metacholine-induced airway obstruction in infants. Pediatr Pulmonol 1994; 18: 308-316.

16. Lodrup Carlsen KC, Carlsen KH, Nafstad P, Bakketeig L. Perinatal risk factors for recurrent wheeze in early life. Pediatr Allergy Immunol 1999; 10: 89-95.

17. Martinez FD, Morgan WJ, Wright AL, Holberg CJ, Taussig LM. Diminished lung function as a predisposing factor for wheezing respiratory illness in infants. $N$ Engl J Med 1988; 319: 1112-1117.

18. Lodrup Carlsen KC. The environment and childhood asthma (ECA) study in Oslo: ECA-1 and ECA-2. Pediatr Allergy Immunol 2002; 13: Suppl 15, 29-31.

19. Lodrup Carlsen KC, Magnus P, Carlsen KH. Lung function by tidal breathing in awake healthy newborn infants. Eur Respir J 1994; 7: 1660-1668.

20. Aas K, Belin L. Standardization of diagnostic work in allergy. Int Arch Allergy Appl Immunol 1973; 45: 57-60.

21. Lodrup Carlsen KC, Carlsen KH, Nikander $\mathrm{K}$, et al. Nebulized budesonide after hospitalization for recurrent 
bronchial obstruction in children younger than 18 months. Pediatr Allergy Immunol 2001; 12: 159-165.

22. Reijonen T, Korppi M, Kuikka L, Remes K. Antiinflammatory therapy reduces wheezing after bronchiolitis. Arch Pediatr Adolesc Med 1996; 150: 512-517.

23. Wennergren G, Strannegard IL. Asthma hospitalizations continue to decrease in schoolchildren but hospitalization rates for wheezing illnesses remain high in young children. Acta Paediatr 2002; 91: 1239-1245.

24. Baxter-Jones AD, Helms PJ, Russell G, et al. Early asthma prophylaxis, natural history, skeletal development and economy (EASE): a pilot randomised controlled trial. Health Technol Assess 2000; 4: 1-89.

25. Medical treatment effectiveness research. 25. RFA: HS-94002 Edn. Rockville, Maryland, USA, US Public Health Service, 1993.

26. Lodrup Carlsen KC, Halvorsen R, Ahlstedt S, Carlsen KH. Eosinophil cationic protein and tidal flow volume loops in children 0-2 years of age. Eur Respir J 1995; 8: 1148-1154.

27. Kraemer R, Graf BU, Casaulta AC, Weder M, Birrer P. Clinical and physiological improvement after inhalation of low-dose beclomethasone dipropionate and salbutamol in wheezy infants. Respiration 1997; 64: 342-349.

28. Altman DG. Relation between two continuous variables. Practical Statistics for Medical Research. London, Glasgow, New York, Tokyo, Melbourne, Madras, Chapman \& Hall, 1991; pp. 277-324.

29. Calpin C, Macarthur C, Stephens D, Feldman W, Parkin PC. Effectiveness of prophylactic inhaled steroids in childhood asthma: a systemic review of the literature. J Allergy Clin Immunol 1997; 100: 452-457.

30. van der Ent CK, Brackel HJL, van der Laag J, Bogaard JM. Tidal breathing analysis as a measure of airway obstruction in children three years of age and older. Am J Respir Crit Care Med 1996; 153: 1253-1258.

31. Lodrup Carlsen KC, Jaakkola JJ, Nafstad P, Carlsen KH. In utero exposure to cigarette smoking influences lung function at birth. Eur Respir J 1997; 10: 1774-1779.

32. Hoo AF, Henschen M, Dezateux C, Costeloe K, Stocks J. Respiratory function among preterm infants whose mothers smoked during pregnancy. Am J Respir Crit Care Med 1998; 158: 700-705. 